\title{
Dietary Influences on Infection and Allergy in Infants: Introduction ${ }^{1,2}$
}

\author{
Henk K. A. Visser* \\ Prof. Emeritus, Sophia Children's Hospital, Erasmus University, Rotterdam, The Netherlands
}

These are the proceedings of an international symposium on infant nutrition held on September 8, 2007 on the occasion of the inaugural lecture of Günther Boehm as Professor of Pediatrics. In recognition of his extensive experience in gastrointestinal physiology during the first years of life, he was appointed to occupy a chair in "Nutrition during Growth and Development" at the Erasmus University Rotterdam (Erasmus Medical Center/ Sophia Children's Hospital).

The topic of the symposium was the development of the immune system in infancy and the possible role of nutritional factors.

After birth, important defense mechanisms of the infant are immature. The intestinal barrier is not fully developed at all levels and can easily be passed by large molecules, and the translocation of bacteria is not efficiently blocked. Additionally, the immune response of thymus-derived immune cells, so-called $\mathrm{T}$ lymphocytes, is skewed toward a reaction that is associated with an increased risk for development of an allergic state, the so-called Th2 pathway. In contrast, the mature and healthy immune system is skewed toward the Th1 pathway, which produces an efficient antimicrobial response including the synthesis of particular antibody isotypes.

The immature condition of the neonate's immune system is largely explained by the fact that development to full maturity requires contact with antigens. Because there is very limited exposure of antigens in utero, antigen-driven immune reactions occur to a significant extent only after birth. Under such circumstances, the infant is highly vulnerable to viral and bacterial infections. This is relevant for term infants but even more so for preterm infants.

Although many questions are still open, there is a consensus that during the postnatal period human milk stimulates the development of the chemical and physical intestinal barrier functions and modulates the immune system toward Th1.

\footnotetext{
${ }^{1}$ Published as a supplement to The Journal of Nutrition. Presented at the symposium "Infant Nutrition" held in Rotterdam, The Netherlands, September 8, 2006. The symposium was organized by the Sophia Children's Hospital, Erasmus University, Rotterdam, The Netherlands, and was cosponsored by Danone Research, Wageningen, The Netherlands. Supplement coordinators: G. Boehm and J. B. van Goudoever, Erasmus University, The Netherlands. Supplement coordinator disclosures: G. Boehm is an employee of Danone Research, the sponsor of the supplement; J. B. van Goudoever, no relationships to disclose.

${ }^{2}$ Author disclosures: H. K. A. Visser, no conflicts of interest.

* To whom correspondence should be addressed. E-mail: brigitte.attenhauser@
} danone.com.
There are many compounds of breast milk that are involved in this process, such as antibodies, hormone-like peptides, prebiotic and antiinfective oligosaccharides, and lipids that provide the precursors for leukotriene synthesis. In addition to these functional compounds, enteral nutrition should provide all nutritive factors required for optimal growth and differentiation of the gastrointestinal tissue.

It is remarkable how much our understanding of nutrition in infancy has advanced during recent decades. The work presented in these proceedings represents the state of the art in a number of relevant areas in fields such as the antiinfective properties of human milk and the physiological role of human milk in the postnatal development of the immune system; the postnatal development of intestinal microbiota as important mediators of the immune system and the intestinal barrier function; and the effects of dietary components such as longchain polyunsaturated fatty acids or prebiotics on the postnatal development of the immune system and the gut barrier integrity.

In recent years an increase in prevalence of atopy and asthma has been observed in industrial countries, and the maturation of the fetal and postnatal development of the immune system in relation to the development of allergy and, most important, strategies for atopy prevention have been discussed.

Although a great deal of experimental and clinical work must still be done to understand the mechanisms, early promising clinical data demonstrate that dietary intervention can help to protect term and preterm infants from infection and can modulate the immune system, which might play an important role in primary allergy prevention in the future.

Other articles in this supplement include references (1-10).

\section{Literature Cited}

1. Wahn UH. Strategies for atopy prevention. J Nutr. 2008;138:1770S-2S.

2. Szépfalusi $Z$. The maturation of the fetal and neonatal immune system and allergy. J Nutr. 2008;138:1773S-81S.

3. M'Rabet L, Vos AP, Boehm G, Garssen J. Breast feeding and its role in early development of the immune system in infants: consequences for health later in life. J Nutr. 2008;138:1782S-90S.

4. Morelli L. Postnatal development of interstinal microflora as influenced by infant nutrition. J Nutr. 2008;138:1791S-5S.

5. Biasucci G, Benenati B, Morelli L, Bessi E, Boehm G. Cesarean delivery may affect the early biodiversity of intestinal bacteria. J Nutr. 2008;138:1796S-800S

6. Chirico G, Marzollo R, Cortinovis S, Fonte C, Gasparoni A. Antiinfective properties of human milk. J Nutr. 2008;138:1801S-6S. 
7. Gottrand F. Long-chain polyunsaturated fatty acids influence the immune system of infants. J Nutr. 2008;138:1807S-12S.

8. Lafeber HN, Westerbeek EAM, van den Berg A, Fetter WPF, van Elburg RM. Nutritional factors influencing infections in preterm infants. J Nutr. 2008;138:1813S-7S.
9. Boehm G, Moro, G. Structural and functional aspects of prebiotics used in infant nutrition. J Nutr. 2008;138:1818S-28S.

10. van Goudoever J, Corpeleijn W, Riedijk M, Schaart M, Renes I, van der Schoor S. The impact of enteral IGF-1 and nutrition on gut permeability and amino acid utilization. J Nutr. 2008;138:1829S-33S. 